\title{
Assessing Airflow Obstruction: When Everything Is Not So Obvious
}

\author{
Riccardo Pellegrino ${ }^{a}$ Vito Brusasco ${ }^{b}$ \\ a Centro di Fisiopatologia Respiratoria e dello Studio della Dispnea, Azienda Ospedaliera S. Croce e Carle, Cuneo, \\ and ${ }^{b}$ Dipartimento di Medicina Interna, Università di Genova, Genova, Italy
}

\author{
This editorial relates to an article by \\ D.C. Stănescu and C. Veriter, published in \\ Respiration issue 71/4/04, pp. 348-352.
}

According to the current international guidelines on lung function testing, airflow obstruction is defined as a disproportionate reduction of flow during a forced expiratory maneuver with respect to the maximal volume that can be expired with a single maneuver $[1,2]$. Taking the forced expiratory volume in $1 \mathrm{~s}\left(\mathrm{FEV}_{1}\right)$ and vital capacity (VC) as surrogates of flow and volume, respectively, airflow obstruction is therefore detected when the $\mathrm{FEV}_{1} / \mathrm{VC}$ ratio falls below the normal range $[1,2]$. If in general, detection of the pulmonary obstructive defect is relatively easy on this basis, it might not be so in some circumstances.

In a recent issue of the Respiration, Stănescu and Veriter [3] described lung function patterns in a small group of relatively young male subjects with no evident history of respiratory or cardiovascular diseases. Both $\mathrm{FEV}_{1}$ and $\mathrm{VC}$ were decreased to similar extents relative to predicted values so that their ratio was normal, but total lung capacity (TLC) was surprisingly normal. According to the current international guidelines, the pattern would be consistent with lung restriction on the basis of the low $\mathrm{FEV}_{1}$ and $\mathrm{VC}$ with a normal $\mathrm{FEV}_{1} / \mathrm{VC}$ ratio, whereas the normal TLC would exclude the restriction.
More than three decades ago, Olive and Hyatt [4] examined the bronchoconstrictor response to inhaled allergens in asthma and documented a decrease in both $\mathrm{FEV}_{1}$ and forced VC of similar extent in a substantial number of subjects. TLC did not change during the bronchial challenge, so that the increase in residual volume (RV) was entirely accounted for by the decrease in VC. Total respiratory resistance increased as a result of airway narrowing. As a tentative explanation, they suggested that the pattern could have been the result of patchy closure of peripheral airways occurring early on forced expiration. That airway closure and/or extreme airflow limitation may occur in humans without changes in TLC has since been repeatedly documented under a variety of different conditions [5-10].

The study by Stănescu and Veriter [3] does unfortunately not bring further or solid evidence that a low $\mathrm{FEV}_{1}$ and $\mathrm{VC}$ with a normal $\mathrm{FEV}_{1} / \mathrm{VC}$ ratio is definitely the result of airflow obstruction besides the fact that most of these subjects had a history of smoking and a lower $\mathrm{CO}$ diffusing capacity than an age-matched control group. Neither does it shed light on the underlying physiologic mechanisms. Yet, this study has the merit to remind us

Riccardo Pellegrino

Centro di Fisiopatologia Respiratoria e dello Studio della Dispnea Azienda Ospedaliera S. Croce e Carle

IT-12100 Cuneo (Italy)

Tel.+390171616805, Fax +390171616798,E-Mail pellegrino.r@ospedale.cuneo.it 
that this pattern does really exist in clinical practice and cannot be ignored for the simple reason that it may be present in a minority of patients. It also tells that if in general VC is a quite good index of flow in practice, it still remains but a mere surrogate of TLC. Thus, if ' $\mathrm{VC}$ is of little use in discriminating between restrictive, obstructive, and mixed ventilatory defects', as clearly stated in the 1993 ERS document [2], then measurement of absolute lung volumes must still play a cardinal part of our daily clinical practice in the lung function laboratory.

\section{References}

1 American Thoracic Society. Lung Function Testing: Selection of reference values and interpretative strategies. Am Rev Respir Dis 1991; 144:1202-1218.

2 Quanjer PH, Tammeling GJ, Cotes JE, Pedersen OF, Peslin R, Yernault JC: Lung volumes and forced ventilatory flows. Report Working Party Standardization of Lung Function Tests, European Community for Steel and Coal. Official Statement of the European Respiratory Society. Eur Respir J 1993;6(suppl 16):5-40.

-3 Stănescu D, Veriter C: A normal $\mathrm{FEV}_{1} / \mathrm{VC}$ ratio does not exclude airway obstruction. Respiration 2004; 71:348-352.
Olive JT, Hyatt RE: Maximal expiratory flow and total respiratory resistance during induced bronchoconstriction in asthmatic subjects. Am Rev Respir Dis 1972;106:366-376.

5 Hyatt RE, Okeson GC, Rodarte JR: Influence of expiratory flow limitation on the pattern of lung emptying in man. J Appl Physiol 1973;35: 411-419.

6 Rodarte JR, Hyatt RE, Cortese DA: Influence of expiratory flow on closing capacity at low expiratory flow rates. J Appl Physiol 1975;39: 60-65.

Guerry-Force ML, Müller NL, Wright JL, Wiggs B, Coppin C, Paré PD, Hogg JC: A comparison of bronchitis obliterans with organizing pneumonia, usual interstitial pneumonia, and small airways disease. Am Rev Respir Dis 1987; 135:705-712.
Pellegrino R, Violante B, Selleri R, Brusasco R: Changes in residual volume during induced bronchoconstriction in healthy and asthmatic subjects. Am J Respir Crit Care Med 1994;150: 363-368.

9 Gibbons WJ, Sharma A, Lougheed D, Macklem PT: Detection of excessive bronchoconstriction in asthma. Am J Respir Crit Care Med 1996;153:582-589.

10 Pellegrino R, Biggi A, Papaleo A, Camuzzini GF, Rodarte JR, Brusasco V: Regional expiratory flow limitation studied with Technegas in asthma. J Appl Physiol 2001;91:2190-2198. 